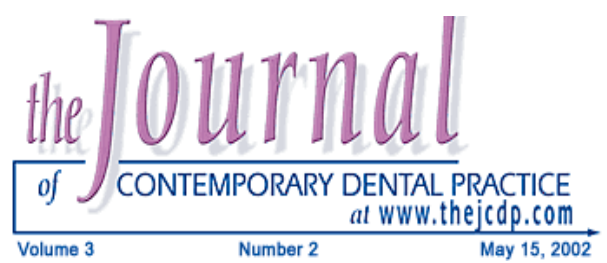

\title{
Microleakage of Packable Composites Used in Post Spaces Condensed Using Different Methods
}

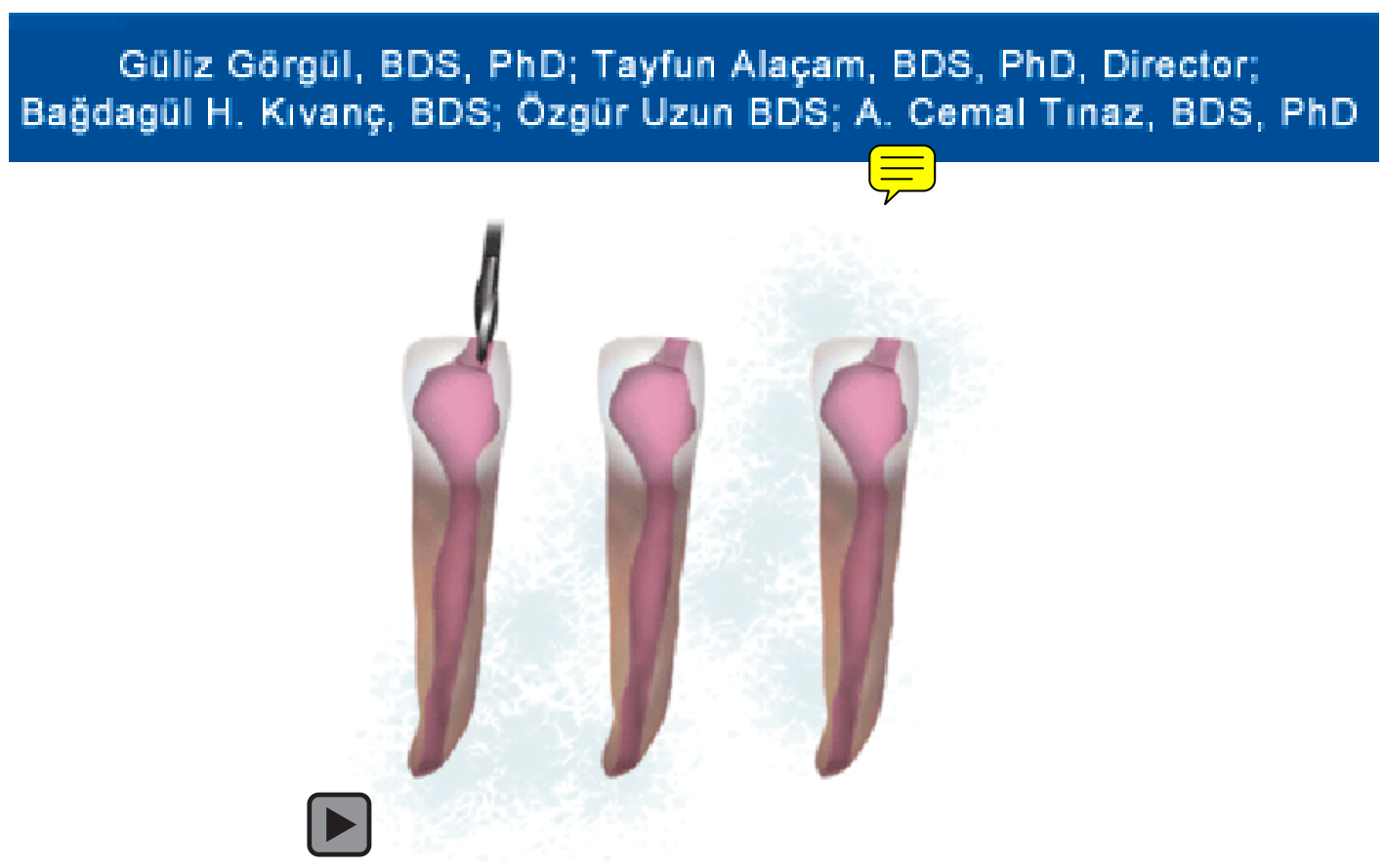

\begin{abstract}
The aim of this in vitro study was to evaluate the apical and coronal microleakage of a packable composite material compacted by either hand or ultrasonic condensers when placed in post spaces. Fortytwo extracted anterior teeth were used. After conventional obturation of the root canals, parallel post spaces $5 \mathrm{~mm}$ in depth and $2 \mathrm{~mm}$ in diameter were prepared using Gates Glidden and diamond burs. A primer and a dentin bonding agent (Prime \& Bond NT) was applied to the etched surface for 30 seconds and light polymerized for 40 seconds. Surefil packable composite resin was inserted in four equal increments and each polymerized for 40 seconds. Half of the specimens were compacted with an ultrasonic tip and the other half with a mechanical hand compactor. After immersion in the dye, the teeth were sectioned longitudinally and dye penetration was evaluated using a stereomicroscope and microleakage recorded in $\mathrm{mm}$. A One-Way Analysis of Variance indicated the two condensing methods were not statistically different $(p>0.05)$. When microleakage was compared within groups, there was also no statistical difference between coronal or apical microleakage $(p>0.05)$. In an in vitro environment, ultrasonic condensers do not offer any advantage over hand condensers. Both the coronal and apical portions of the root had microleakage indicating that regardless of the condensation method and the use of a packable composite, there is still microleakage that could potentially create further clinical problems.
\end{abstract}

Keywords: Microleakage, packable composite, resin post

Citation: Görgül G, Alaçam T, Kivanç BH, et. al. Microleakage of Packable Composites Used in Post Spaces Condensed Using Different Methods. J Contemp Dent Pract 2002 May;(3)2: 023-030.

(c) Seer Publishing 


\section{Introduction}

Endodontically treated teeth are generally weakened as a result of decay, previous restorative procedures, and endodontic access preparation. To prevent further destruction of these teeth, a protective restoration is necessary to create retention and resistance. ${ }^{1}$ Dentin bonding systems, special composite resin core systems, and light curing composite resins are recommended to be used for the restoration of endodontically treated teeth. $^{2}$ It has also been demonstrated that light-cured composite resins can be used in root canals. ${ }^{3}$

The recent introduction of condensable or packable composites offers the possibility of replacing amalgam with composites as a major restorative material for posterior restorations. Physical properties of packable composites such as a reduced initial polymerization shrinkage, a coefficient of thermal expansion close to that of the tooth structure, and a modulus of elasticity similar to that of amalgam have been reported. ${ }^{4}$ There are also improvements in their handling properties that should ease marginal adaptability. These composites are supposedly not sticky because of modification of the filler particles by the manufacturer. They do not slump; their high viscosity allows for carving the composites without slumping. These resins can be handled and placed with techniques similar to those used for amalgam. ${ }^{4}$

To achieve a successful endodontic therapy, the most important criterion is the well adaptation of the filling material to dentin walls and to prevent microleakage apically and coronally.

Polymerization shrinkage has been often mentioned as being one of the most significant factors responsible for the failure of composite restorations $^{5,6}$ especially for the marginal leakage at the tooth/restoration interface. In order to reduce this problem, many restorative techniques and new materials have been suggested. ${ }^{7}$ Because of the suitable working properties, packable composites could be used in root canals as a replacement for posts or amalgam and as a core build-up material.

The aim of this study was to evaluate if the use of a packable composite resin when condensed with an ultrasonic or a hand condenser provides less microleakage at the apical or coronal portions of the post space.

\section{Materials and Methods}

Forty-two extracted maxillary centrals and laterals were used for the study. The coronal portion of the tooth was removed at the enamel-cement junction using

Apical

Region a low speed diamond saw. After conventional debridement, mechanical preparation and filling procedures were made. The canals were fitted with a size 40 master cone gutta percha (DendiaWerk gmbH P.0.131, A-1239 Vienna, Austria) and AH 26 (Dentsply De Trey GmBH Konstanz, Germany) sealer and gutta percha was compacted using a continuous wave technique ${ }^{8}$ (System-B, Analytic Technology, Redmond, USA). Parallel post spaces were then prepared to a $5 \mathrm{~mm}$ depth and $2 \mathrm{~mm}$ diameter using a number 6 Gates Glidden drill (Mani, INC., Tachigi-ken, Japan) and diamond burs (Komet 837/016- Brasseler, LemgoD).

The prepared canals were then etched with 35\% phosphoric acid etching gel (Ultradent Products, Inc., Utah, USA) for 15 seconds, rinsed with water, and air-dried with an air syringe for 20 seconds. Prime and Bond NT bonding agent (Caulk/Dentsply, Milford DE, USA) was applied to the etched surface for 30 seconds and light polymerized (Hilux Dental Curing Light, Model No 200, Benlioglu Dental Inc., Turkey) for 40 seconds. Surefil (Dentsply, DeTrey, Surrey, UK), a packable composite resin, was packed in approximately four equal increments. After each increment, the resin

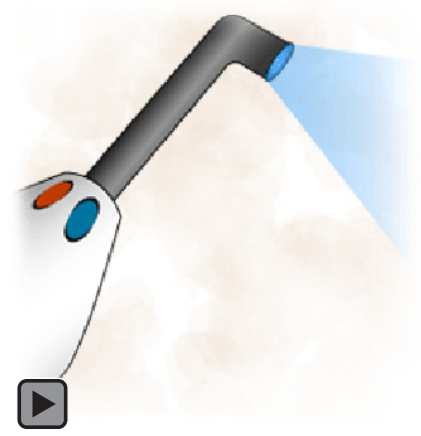




Table1. Statistical results of the data.

\begin{tabular}{|l|c|c|c|c|c|c|}
\hline & \multicolumn{3}{|c|}{ Hand Compaction } & \multicolumn{3}{c|}{ Ultrasonic Compaction } \\
\cline { 2 - 7 } & $n$ & Mean & Std. Dev. & $n$ & Mean & Std. Dev. \\
\hline Coronal & 10 & 0.8225 & 0.5848 & 10 & 1.1125 & 0.6301 \\
\hline Apical & 10 & 1.3100 & 0.5717 & 10 & 1.1400 & 0.6716 \\
\hline
\end{tabular}

was light polymerized for 40 seconds. Twenty specimens were compacted with an ultrasonic endo-plugger (Suprasson ${ }^{\circledR}$ P5 Booster, Pierre Rolland, France) used at maximum power, and the other 20 specimens were packed with a hand compactor (Dentsply, Maillefer, ch-1338 Ballaigues, Switzerland). Then the apical part of the teeth that still had the gutta percha was removed and composite filled roots were stored in water of $21^{\circ} \mathrm{C}$ for 24 hours after which the teeth were subjected to 100 thermocyclings. Each cycle consisted of a 5 minute bath at $37^{\circ} \mathrm{C}$, a 5 second bath at $5^{\circ} \mathrm{C}$, a 5 minute bath at $37^{\circ} \mathrm{C}$, and a 5 second bath at $55^{\circ} \mathrm{C} .^{9}$

For the root microleakage evaluation, 10 teeth from each group were coated with 2 layers of nail varnish except $2 \mathrm{~mm}$ of the root. For the coronal microleakage evaluation, 10 teeth from each group were coated with 2 layers of nail varnish except the coronal $2 \mathrm{~mm}$ of the tooth. The teeth were then stored in $1 \%$ methylene blue for 24 hours. As a negative control, the post space of two teeth were filled with composite, and the teeth were completely coated with nail varnish and stored in methylene blue for 24 hours. After inmersion in methylene blue, the teeth were rinsed, sectioned longitudinally, and examined under X6 magnification by stereomicroscope and dye penetration was recorded in $\mathrm{mm}$. The results were statistically evaluated using a One-Way Analysis of Variance test.

\section{Results}

Results of this study can be seen in Table 1 and Figure 1a-b. All the roots had microleakage that ranged from a mean of $0.82 \mathrm{~mm}$ in the coronal portion of the root to a mean of $1.31 \mathrm{~mm}$ leakage at the apical portion of the root. When condensing techniques were compared, neither hand nor ultrasonic method was statistically different for both the coronal and apical parts ( $p>0.05)$.

As shown in Table 1 and Figure 1a-b, when the apical and coronal microleakage measurements were compared within each group, although there seems to be more microleakage at the apical region compared to the coronal, there were no statistically significant differences between the apical and the coronal parts of the teeth $(p>0.05)$. There was no leakage in the negative controls.

\section{Discussion}

Badly broken down pulpless teeth usually need root retained restorations. Endodontically treated teeth are not strengthened by the placement of the posts, but retention of the restoration is enhanced by the use of a post. It is thought that filling the post space with a new generation of composites and dentin bonding agents may produce superior adaptation to the dentinal walls. ${ }^{10}$ Tjan et. al. ${ }^{11}$ found the retentive value of the composite reinforcement bounded to the root canal wall was significantly higher than that of a custom cast post luted to the root canal wall with zinc phosphate ce-

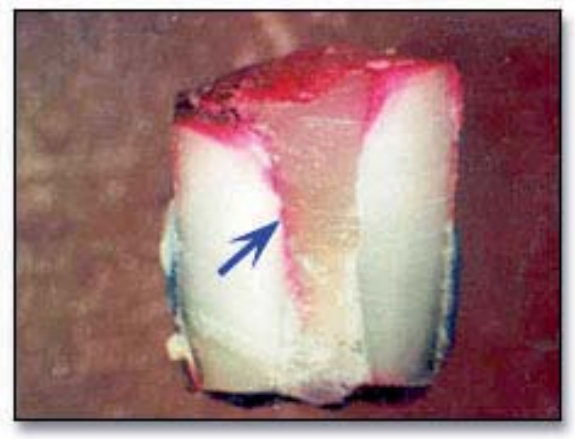

Figure 1b. Apical Microleakage 


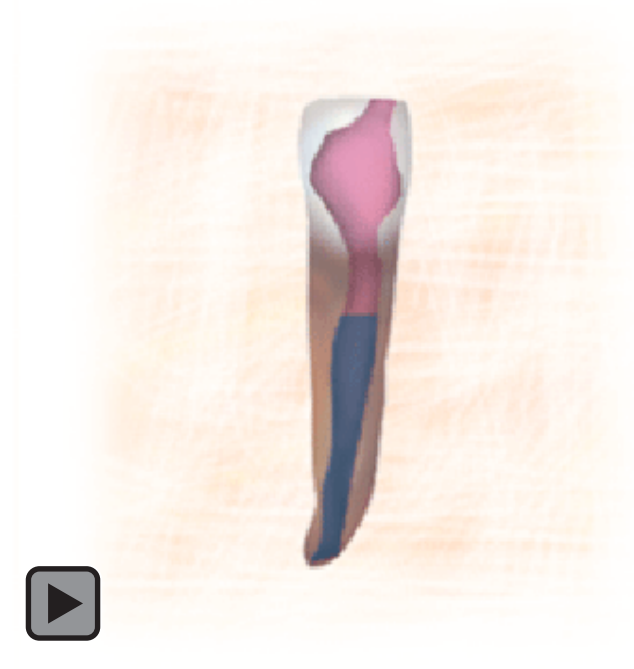

ment. However, placing an even layer of a dentin bonding agent in the canal walls of the post space is difficult. If a spot in the canal is left without a coat of the dentin bonding agent when the composite polymerizes, it could lead to microspaces in the canal and eventually microleakage. ${ }^{4,12,13}$ The use of self-polymerized composite has better working characteristics, since it allows sufficient time and control for proper placement into the canal, however, the use of self-polymerized composites has declined because of problems with proper mixing and incorporation of oxygen into the mix. Light polymerized composites are the standard in dentistry, and recently a new generation of highly filled composites (packable composites) has been introduced. Some manufacturers and some investigators claim that packable composites can be bulk polymerized to a depth of 4 to $5 \mathrm{~mm}{ }^{10,14}$ Unfortunately, complete polymerization cannot always be guaranteed when the composite is placed in increments larger than $4-5 \mathrm{~mm}$, mainly because the curing light might not have the sufficient light intensity or the bulk of the intraradicularly placed composite blocks the passage of light. ${ }^{10} \mathrm{~A}$ pilot study we conducted has indicated that a greater depth of cure was achieved when the composite was polymerized in smaller increments. For this study, the composite was condensed in 4 layers and each layer light-polymerized for 40 seconds with each layer being about $1.25 \mathrm{~mm}$ in depth.
Half of the roots were condensed by an ultrasonic plugger aiming to eliminate microspaces occurred during packing and to reduce microleakage. However, ultrasonic packed specimens had no significant difference in microleakage than the specimens that were hand condensed.

In this study, the apical third obturated by gutta percha and $\mathrm{AH} 26$ sealer was removed and only the post part that was obturated with composite was left for evaluation. The rational for eliminating the apical third of the root was to evaluate the obturation capability of a posterior composite used as post material. We aimed to eliminate the other variations such as microleakage of the gutta percha and canal sealer that may affect the apical microleakage directly. By using a packable composite and two different condensation methods, we aimed to show the exact microleakage and adaptation of the packable composite apically without any other affecting factors.

There are many studies comparing the techniques effecting the microleakage and adaptation of Class II packable resin-based composites ${ }^{15,16,17}$ but we could not find any study evaluating the microleakage of packable composite resins condensed ultrasonically and polymerized in increments in a root canal.

\section{Conclusion}

Within the limitations of this in vitro study, it can be said that ultrasonic condensation of the packable composites does not provide any advantage in adaptation over hand compaction when results are evaluated using a microleakage method. All condensation methods produced microleakage, and the clinical repercussions of this technique need to be further evaluated. While this in vitro study does not conclude the same result would occur in a real clinical situation, that question could be the basis for further research in this area. 


\section{References}

1. Plasmans PJ, Welle PR, Vrijhoef MM. In vitro resistance of composite resin dowel and cores. J Endod. 1988 Jun;14(6):300-4. No abstract available.

2. Saupe WA, Gluskin AH, Radke RA Jr. A comparative study of fracture resistance between morphologic dowel and cores and a resin-reinforced dowel system in the intraradicular restoration of structurally compromised roots. Quintessence Int. 1996 Jul;27(7):483-91.

3. Anic I, Shirasuka T, Matsumato K. Scanning electron microscopic evaluation of two compaction techniques using a composite resin as a root canal filling material. J Endod. 1995 Dec;21(12):594-8.

4. Tung FF, Estafan D, Scherer W. Microleakage of a condensable resin composite: an in vitro investigation. Quintessence Int. 2000 Jun;31(6):430-4.

5. Bausch JR, de Lange K, Davidson CL, et al. Clinical significance of polymerization shrinkage of composite resins. J Prosthet Dent. 1982 Jul;48(1):59-67.

6. Tjan $\mathrm{AH}$, Bergh $\mathrm{BH}$, Lidner $\mathrm{C}$. Effect of various incremental techniques on the marginal adaptation of class II composite resin restorations. J Prosthet Dent. 1992 Jan;67(1):62-6.

7. Christensen GJ. Overcoming challenges with resin in Class II situations. J Am Dent Assoc. 1997 Nov;128(11):1579-80. No abstract available.

8. Buchanan LS. The continuous wave of obturation technique: 'centered' condensation of warm gutta percha in 12 seconds. Dent Today. 1996 Jan;15(1):60-2, 64-7. No abstract available.

9. Neiva IF, de Andrada MC, Baratieri LN, et. al.. An in vitro study of the effect of restorative technique on marginal leakage in posterior composites. Oper Dent. 1998 Nov-Dec;23(6):282-9.

10. Lui JL. Enhanced post crown retention in resin composite-reinforced, compromised, root-filled teeth: a case report. Quintessence Int. 1999 Sep;30(9):601-6.

11. Tjan AH, Tjan AH, Sun JC. Retention of Luminex post system. Oral Health. 1997 Aug;87(8):31-5. No abstract available.

12. Bausch JR, de Lange K, Davidson CL, et al. Clinical significance of polymerization shrinkage of composite resins. J Prosthet Dent. 1982 Jul;48(1):59-67.

13. El-Mowafy OM, Milenkovic M. Retention of paraposts cemented with dentin-bonded resin cements. Oper Dent. 1994 Sep-Oct;19(5):176-82.

14. Lui JL. Depth of composite polymerization within simulated root canals using light-transmitting posts. Oper Dent. 1994 Sep-Oct;19(5):165-8.

15. Neiva IF, de Andrada MC, Baratieri LN, et. al.. An in vitro study of the effect of restorative technique on marginal leakage in posterior composites. Oper Dent. 1998 Nov-Dec;23(6):282-9.

16. Gallo JR 3rd, Bates ML, Burgess JO. Microleakage and adaptation of Class II packable resin-based composites using incremental or bulk filling techniques. Am J Dent. 2000 Aug;13(4):205-8.

17. Beznos C. Microleakage at the cervical margin of composite Class II cavities with different restorative techniques. Oper Dent. 2001 Jan-Feb;26(1):60-9.

\section{About the Authors}

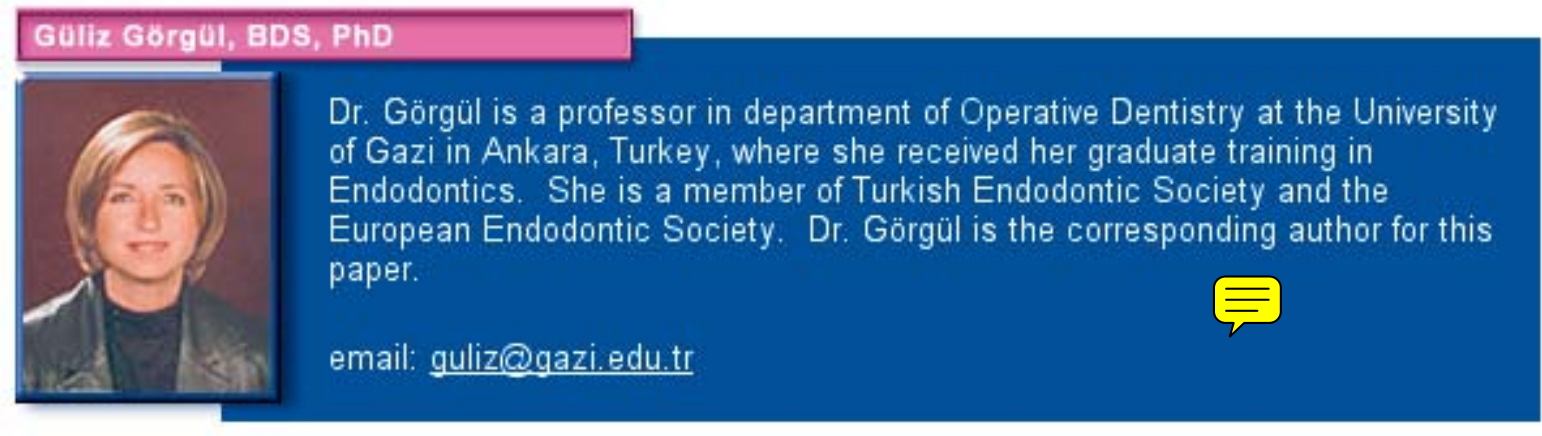




\section{Tayfun Alacam, BDS, PhD, Director}

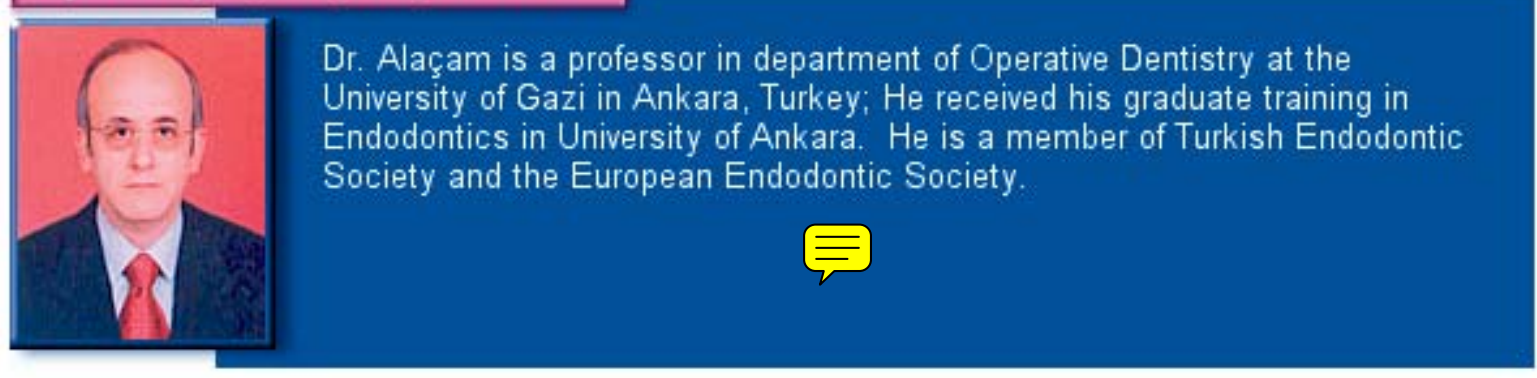

\section{Bagdagul H. Kivanc, BDS}
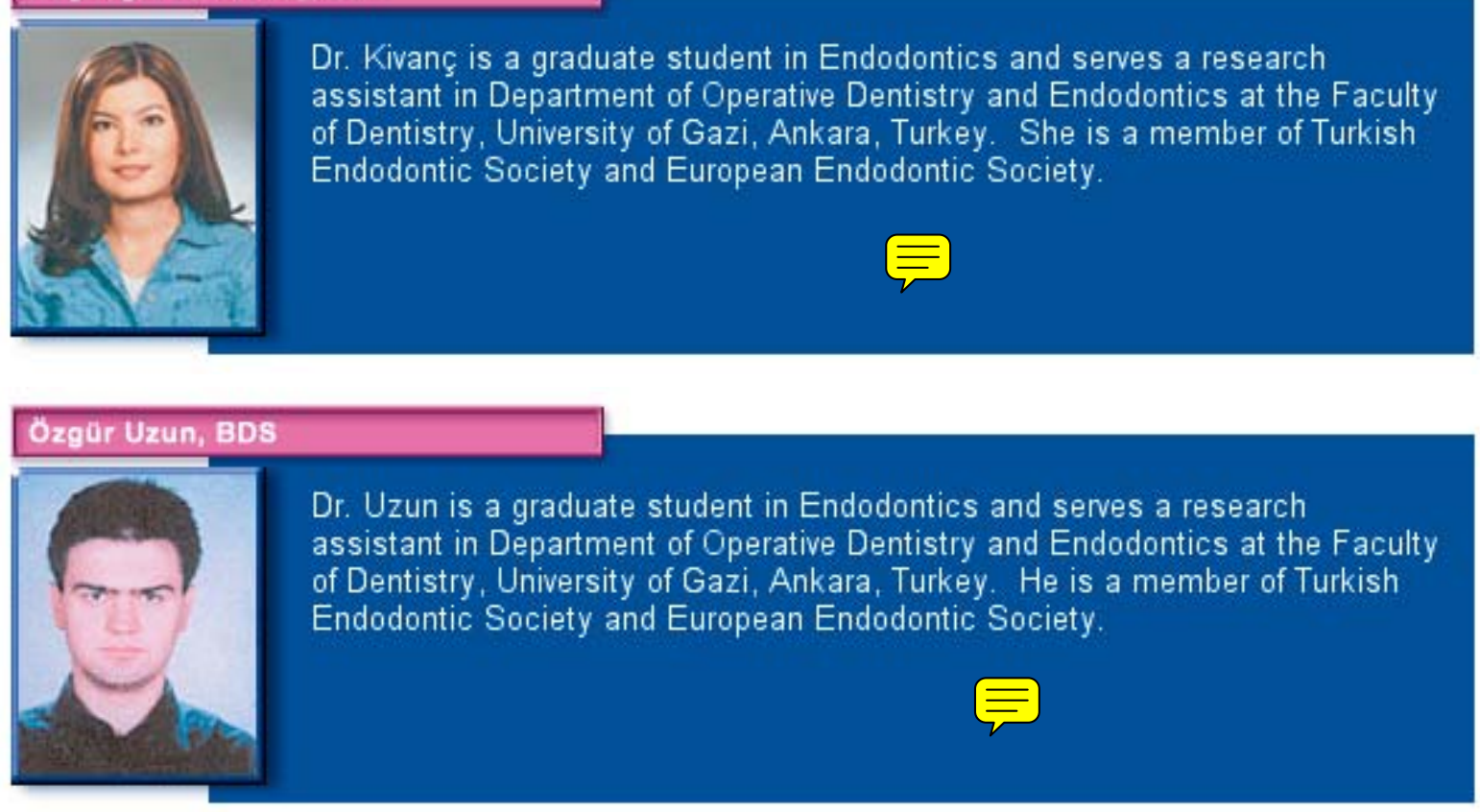

\section{A. Cemal Tinaz, BDS, PhD}

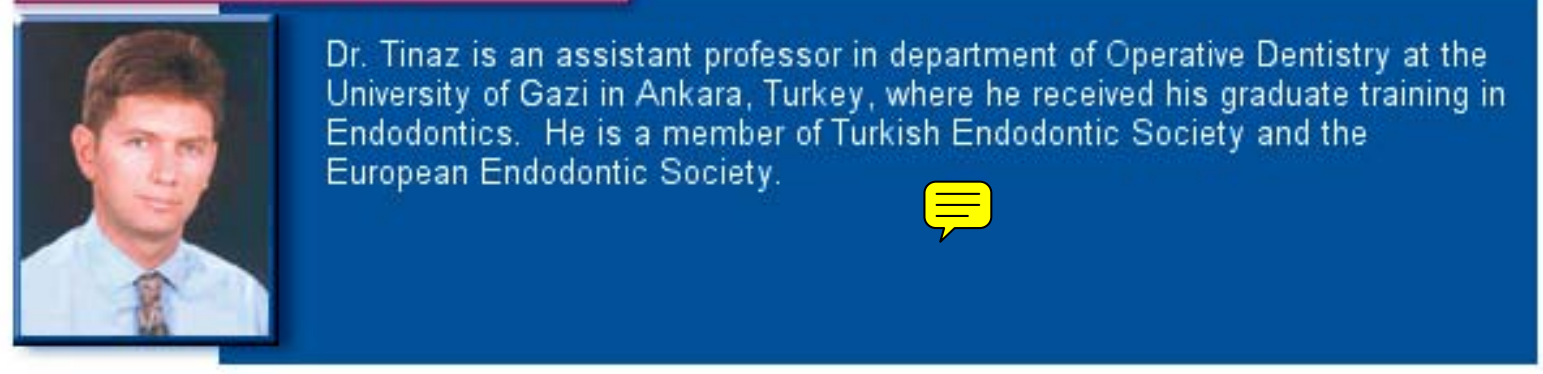

